\title{
Defeating The Bandwidth: A Model For Integrating Web And CD- ROM Based Training Solutions
}

\author{
Carlos R. Morales \\ Purdue University
}

\begin{abstract}
This paper describes the development of a distance learning system for classroom instruction. The system combines traditional CD-ROM technology, used to achieve a high level of media-rich content, with web technologies, used for dynamic media updating and performance tracking. The system also employs Microsoft Media Services and ActiveX components for application sharing, two-way video teleconference, and oneway video multicasting.

\section{Introduction}

There is a tremendous advantage to integrating CD-ROM based interactive multimedia (CDIM) and TCP/IP services such as HTTP for Computer Aided Instruction/Computer Based Training (CAI/CBT). By using CDIM for media delivery and Web based technologies for control, communications, updating content, and performance tracking it is possible to build a system that can deliver multi-sensory content in a much more dynamic manner than through traditional multimedia or the Web alone. This project interfaces available WWW and CDIM technologies in an unified environment that allows instructors to deliver distance instruction with many of the media delivery benefits of a traditional classroom by providing a framework for lectures, out of class work (homework), tests, and teacher/student conferences.
\end{abstract}

\section{Background}

The last few years have witnessed the penetration of the Web into mainstream corporations. The Yankee Group tells us that by the year 2002 corporations will spent 44 billion dollars on internet related services (Duvall, 1999). The penetration of the intranets in the corporate environment has created an opportunity for Web based training. Dugan tells us, "The catalyst for the rise of Web based training is the increasing need for corporate training, particularly in the area of technology. Whenever a company upgrades its OS, e-mail package, or word-processing application, the staff must be trained." (Dugan, 1998) "According to Montgomery Securities analyst Ellen Julian, the $\$ 16$ billion world market for tech training will hit \$28 billion in the year 2001. Managers at Merrill Lynch, MCI, and other companies that use Web based training say that web based programs offer significant benefits over traditional paper and classroom sessions and CDROM (Violino, 1998). 
Two main impetuses for the use of intranets for training have been financial gain and content flexibility. Sun has reported that by using technology based training it expects to cut its sales training cost by as much as 50 percent (Kahn, 1997). GTE estimates that prior to putting its classes on-line, it spent approximately $\$ 7,000.00$ per student sent to Northern Telecom for training. In contrast to CD-ROM based modules, web instruction is more flexible because "updating courseware [on CD-ROM] ... involved recalling old versions, pressing new $\mathrm{CDs}$, and redistributing them across remote sites. When the Intranet is finally in place, courseware can be revised by logging on to update content for all users at once." (Abernathy, 1998)

While the flexibility to change content across geographically remote locations is a tremendous benefit for Web based training solutions, CD-ROM based delivery dominates when it comes to delivering high bandwidth content such as digital audio or video. Kahn tells us "... companies have opted to use CD-ROM technology for training, bypassing the slow speed and lack of video associated with Net-based tools." (Kahn, 1997) It is not uncommon to find $24 \mathrm{x}$ and even $32 \mathrm{x}$ CD-ROMs at training locations capable of delivering sustained rates of 3.7 megabytes per second. Yet, it's not very common for individuals to get sustained rates above 100 kilobits per seconds at their training stations. To effectively deliver the quality of multimedia that the public has come expect, it is imperative to achieve a high level of sustained bandwidth. Ethernet (10-BaseT) is 25\% slower than a 12x CD-ROM and 100-BaseT is slower than many production-level hard drives (Seagate, 1999). The majority of multimedia users are accustomed to accessing media content at 3600 kilobytes per second or faster. The bandwidth is just not there for content creators to fully exploit the potential of multimedia over intranets or the Internet.

In addition to bandwidth problems, Web based solutions are hurt by relying on the browser interface which favors user centric control. For CAI/CBT, the trainer needs to orchestrate the delivery of information to maximize the achievement of the instructional objectives. Mainstream browsers such as Netscape or Internet Explorer were never designed with this level of control in mind. Java Applets, JavaScript, and ASP applications do provide some alleviation to this problem, but the fact still remains that the level of control that most CAI/CBT authors crave is better addressed by traditional multimedia authoring packages such as Macromedia Director or Authorware.

A plausible solution for harnessing the dynamic nature of Web based solutions while maintaining the media delivery capabilities of CD-ROM solutions is to use TCP/IP services to provide the control and communication structure for a server/client based multimedia system and host the actual media components locally on the client's hard drive or CD-ROM. This would provide the central control of a Web based system and eliminate bandwidth problems by accessing media files off the client's local. With these capabilities it is possible to author CAI/CBT solutions that uploads the user's performance to a central database, downloads new lessons, and allows the learner to "chat" with other users.

Many technological components have emerged recently to allow developers to produce hybrid Web/CDIM solutions. Macromedia Director 7 and Authorware 5 provide a 
variety of TCP/IP functions such downloading media assets through FTP or HTTP. Allegiant and Tubuleiro market plug-ins, which allow multimedia authors to fetch web content from within CDIM applications. Macromedia's Active-X controller, allows the use of Active-X controls within Director and Authorware. This makes it possible to increase the functionality of multimedia applications written in Director or Authorware by utilizing any Component Object Model (COM) objects registered on the system. Active- $X$ objects are language independent chunks of code that provide the invoking program with functionality ranging from simple calendars to speech recognition and even serial device control. Because the Active-X controls shield much of the complexity of the COM objects from the multimedia author, very little low-level programming needs to be done in order to integrate these into Director or Authorware.

\section{Implementation}

In developing the Unified Multimedia Delivery System (UMDS), the author looked at the traditional classroom as a guide for integrating available technologies. The author identified the areas that needed to be included in the system for it to mimic the freedom of media delivery available in a traditional classroom. Prior to selecting technological components or programming the UMDS, the author categorized activities present in a traditional classroom into: lecture, homework, tests, and instructor/student conferences. Table 1 details the operational definition used by the author in defining the areas.

\begin{tabular}{|l|l|}
\hline \multicolumn{1}{|c|}{ Identified Area } & \multicolumn{1}{c|}{ Operational Definition } \\
\hline Lecture & $\begin{array}{l}\text { Any session in which the instructor delivers visual and } \\
\text { auditory materials to a group of learners. }\end{array}$ \\
\hline Homework & $\begin{array}{l}\text { Any activity in which the learner is expected to } \\
\text { complete a task outside of class. The student is } \\
\text { expected to retrieve the instructional materials } \\
\text { himself/herself, complete an assignment, and turn-in } \\
\text { his/her work. }\end{array}$ \\
\hline Test & $\begin{array}{l}\text { Any activity in which the learner is asked to } \\
\text { demonstrate his/her mastery of the instructional } \\
\text { objectives. }\end{array}$ \\
\hline $\begin{array}{l}\text { Student/Instructor } \\
\text { Conference }\end{array}$ & $\begin{array}{l}\text { Any live interaction between the learner and the } \\
\text { instructor or the administrative materials for the course. } \\
\text { This would include one-on-one live video conferences, } \\
\text { checking records, etc. }\end{array}$ \\
\hline
\end{tabular}

Table 1. Activities in Traditional Classroom

With the main areas of the traditional classroom categorized, the author devised a system that best enhanced the activities that occur within each of these realms. An analysis of the identified areas enabled the author to select the appropriate configuration for the technological components used in developing the UMDS. The author elected to look at 
the areas in term of communication flow, pace control, synchronicity, and access to information.

First, the author identified the direction and amount of communication flow in each of the areas. For example, during a lecture the communication flow would almost entirely go from the instructor to the student. This did not negate the need for feedback, but dictated that the technological solution allocated most of the bandwidth from the instructor to the student. Provisions had to be made for bi-directional video teleconferencing and CDROM delivered video. In both cases, the instructor needed the option of controlling the client's video. For the homework and test portions, communication flowed in both directions at a relatively low data rate. Most of the data would be delivered in text form with occasional use of video and/or sound clips.

Second, the author examined the pace of instructional delivery. During the lecture component, the instructor alone would set the pace. The instructor would have the option of taking questions while lecturing, or deferring them until the end of lecture. The UMDS would allow the lecturer to control the video feed, even if it was delivered off CD-ROM. For the homework component, the student would be able to go through the materials at his/her own leisure. Thus, no provision for interactive control or video delivery would need to be implemented. For the test component, the student would be allowed to set the pace at which he/she proceeded through the material, within the confines of any time limits set by the instructor. No mechanism would be needed to time each individual question. During conferences, both participants would set the pace as a result of their interactions. This would necessitate immediate feedback in both directions.

Third, the author considered the presence of the instructor during the activity. For homework the instructor does not need to be present. Students can complete homework assignments without the direct participation of the instructor. This area could be implemented using asynchronous technologies. Lecture and conference components, on the other hand, necessitated the presence of the instructor. Even if the lecture were delivered off CD-ROM, all of the students and the instructor would need to go through the experience simultaneously. This would ensure that all students would be watching the same content simultaneously and could engage in a live question/answer discussion.

Fourth, the author considered the accessibility of instructional materials. While students would be able to freely access homework materials, the instructor would need to be present for tests and lectures. An exception would be archived lectures, which the students could view at their leisure. This is crucial because it would force all students to "attend" class and go through the communal lecture experience much like in a traditional classroom. For tests, the students would also be denied free access to the materials. The test would be delivered on the CD-ROM or from the web in encrypted form. Only after the instructor has sent the unlock key would the test be unlocked. Table 2 presents this information in tabular form. 


\begin{tabular}{|l|l|}
\multicolumn{1}{c|}{\begin{tabular}{c}
\multicolumn{1}{c|}{ Classroom } \\
Activity
\end{tabular}} & \multicolumn{1}{c|}{ Activity Characteristics } \\
\hline Lecture & $\begin{array}{l}\text { Communication flow: Mostly one } \\
\text { way } \\
\text { Pace control: Instructor } \\
\text { Scheduled: Yes } \\
\text { Instructor Present: Yes } \\
\text { Free access to Materials: No }\end{array}$ \\
\hline $\begin{array}{l}\text { Out of class work } \\
\text { (homework) }\end{array}$ & $\begin{array}{l}\text { Communication flow: Two Way } \\
\text { Pace control: Student } \\
\text { Scheduled: No } \\
\text { Instructor present: No } \\
\text { Free access to materials: Yes }\end{array}$ \\
\hline Test & $\begin{array}{l}\text { Communication flow: Two Way } \\
\text { Pace control: Student } \\
\text { Scheduled: Yes } \\
\text { Instructor present: No } \\
\text { Free access to materials: No }\end{array}$ \\
\hline
\end{tabular}

Table 2. Classroom Activity Analysis

To achieve the identified functionality, Macromedia Director 7 and embedded Active-X components were used. Director provided the interface and media delivery capabilities, NetLingo and the Macromedia Multiuser Server provided the TCP/IP calls necessary for creating a message loop between the client and server applications, Active-X components provided application sharing and allowed the client stations to receive live video streams, and Microsoft Media Services provided the ability to send a live multicast stream.

Crucial to the development for the UMDS was the establishment of a control mechanism among the client applications. By using Net Lingo to create a chat channel among the client applications and using Macromedia Multiuser Server as a hub to reflect messages, the author established an inter-application message loop. Event handlers were then written to intercept events sent through this mechanism. This provided the needed control among the individual program pieces.

The author then focused on developing the mechanism for the delivering CD-ROM based video. A Microsoft Access database was created on the server with four fields --- the net path to the video file, a description of the lecture, the version number of the lecture, and the date for the lecture presentation. By only saving the path of the lectures in the database instead of the actual data, transmission time between server and client was minimized.

To synchronize the lecture video segments among the clients and the server three mechanisms were employed. First, the server was programmed to push a new database file onto the client applications numerous times throughout the day. Upon receipt, the 
client application compares the database version of the lectures on the database with the versions on the local hard drive. If discrepancies arise, the client stations download the new files. This mechanism insures that the clients have the newest lectures most of the time. For last minute changes, the clients are programmed to check their database with the master server database fifteen minutes before lecture starts. If the versions differ, the client pulls the newest lecture off the server. The retrieval of the video files is accomplished through NetLingo's FTP functions and by communication between the client and the server through the chat based virtual message loop. DataGrip was used to access the Microsoft Access database from within Director. An option to manually force an update was also placed on all of the clients.

At this point the application correctly handled video lectures delivered in advance to the clients. The system could adjust to any changes in video as long as these changes occurred within 15 minutes before class time. Now it was time to implement a mechanism for live video lectures. A message handler was programmed into the clients allowing the server to switch to a live video feed at any point. After experimenting with a few alternatives, the author decided to use Microsoft's Media Server to multicast a video stream. An embedded MS Media Player Active-X control allowed the author to receive video within the Director application. The Macromedia's Active-X controller allowed the author to embed Active-X controls within the Director application without having to program the COM API directly. By writing a few event handlers and accessing a few provided methods, the author was able to harness the power of these applications from within the Director 7 UMDS.

Microsoft's Media Services provided the means for streaming very high quality video from the server to the clients. Provisions for multicasting and unicasting made the use of this technology very attractive. By setting the up the system to multicast, the instructor was able to send a very high quality MPEG-4 stream from the server to a virtually unlimited numbers of clients. Rates as high as 3.25 megabits per seconds can achieve decent full-screen full-motion video. The decision to utilize Microsoft's Media Services for video transmission necessitates additional hardware on the server side. Two additional machines were needed. One machine housed a video encoding card and ran Microsoft Media Encoder. This machine was dedicated to digitizing the video and encoding it into MPEG-4 during live video transmission. A second machine ran Windows NT Server 4.0, Microsoft Media Server, and Information Server 4.0. This machine was responsible for taking the stream coming from the encoder machine and multicasting it. See Figure 1 for the overall server organization. 


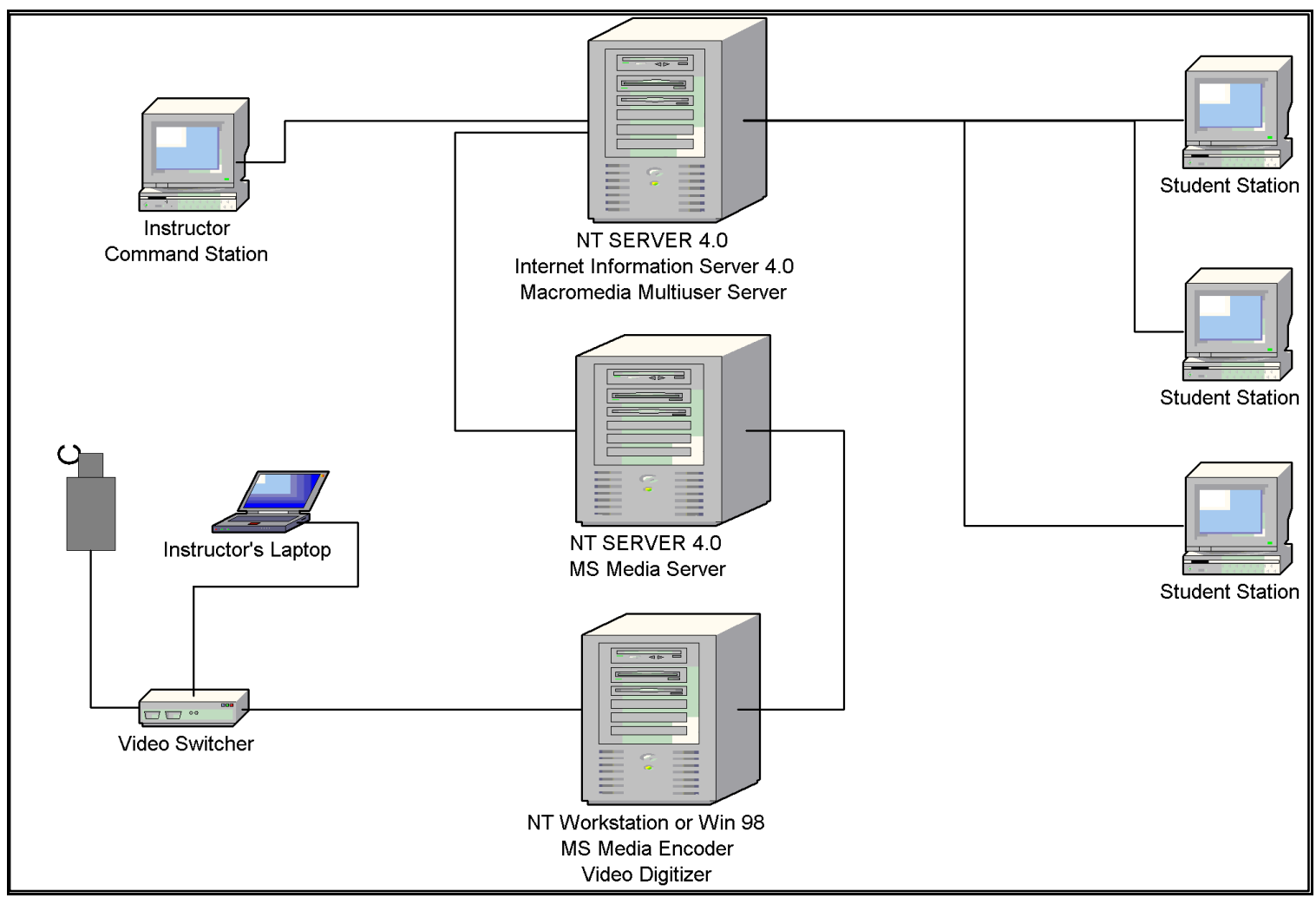

Figure 1. UMDS System Server/Client Organization

The server could instruct the clients to show full screen MPEG-I video from their own hard drive or CD-ROM, or to accept a very high quality MPEG-4 live video stream. A mechanism for live video and/or audio from the clients back to the server was still needed. The author elected to use NetMeeting for this purpose because it could be implemented on the clients without requiring multiple machines and it could be embedded within the host Director application. An additional benefit was that video transmitted by NetMeeting is less bandwidth intensive than that generated by Microsoft's Media Services. This solution allocated most of the bandwidth for instructor-originated video. NetMeeting, also, provided application sharing and collaboration, file transfer, and a whiteboard.

The addition of a mechanism for live video completed the lecture module. The instructor could deliver CD-ROM based video lectures or switch to a live lecture at any point, demonstrating any computer application including PowerPoint slides through the use of application sharing. Additionally, students could ask questions through a lower bandwidth video connection.

The homework and test modules were implemented by using Active Server Pages to deliver the content to the Director application. An embedded Microsoft Web Browser Active-X component allowed the clients to access the content without having to spawn an external browser. The reliance on ASP necessitated the use a PC running Windows NT Server 4 and Microsoft Information Server 4.0. A benefit of using this technology was 
that it made all of the server side technology, such as server-side database access or banner rotation, available to our application. Using the embedded web browser allowed the author to control the content the user sees. Because the Director application retrieves the web content and presents the information to the user transparently through its own interface, the user never gets a chance to "browse the web." ASP pages for the homework assignments were generated using Macromedia Drumbeat 2000 ASP Edition. The learner's responses were routed to an Access database on the IIS server by creating an Active-X Data Objects connection. Using this mechanism IIS is able to interface with any ODBC compliant database. Tests were created in the same manner with the exception of added security measures. The ASP pages were programmed to only accept input from a predetermined IP address and to request login/password information prior to submittal. Event handlers on the client applications were also programmed to allow the instructor to start and stop the administration of tests.

The conference section was designed for three main purposes. First, it allowed the students and the instructor to talk in a private environment much like when a student visits a professor during office hours. Second, it provided the instructor with the ability to demonstrate software techniques and/or assist the students with portions of assignments. Third, students was provided with a way to see their progress and grades in the course. The NetMeeting Active- $X$ component provided all of the functionality needed for the first two activities. The video conferencing features allowed the student and the instructor to speak in a live video teleconference. The collaboration and application sharing tools allowed the instructor to help the student with his/her assignment or to demonstrate techniques by broadcasting desktop applications. Finally, the author implemented a Microsoft spreadsheet Active-X control to allow the students to access the instructor's grade book. Password protection insures that students only have access to their own grades. See Figure 2 for a detail look of the UMDS internal structure.

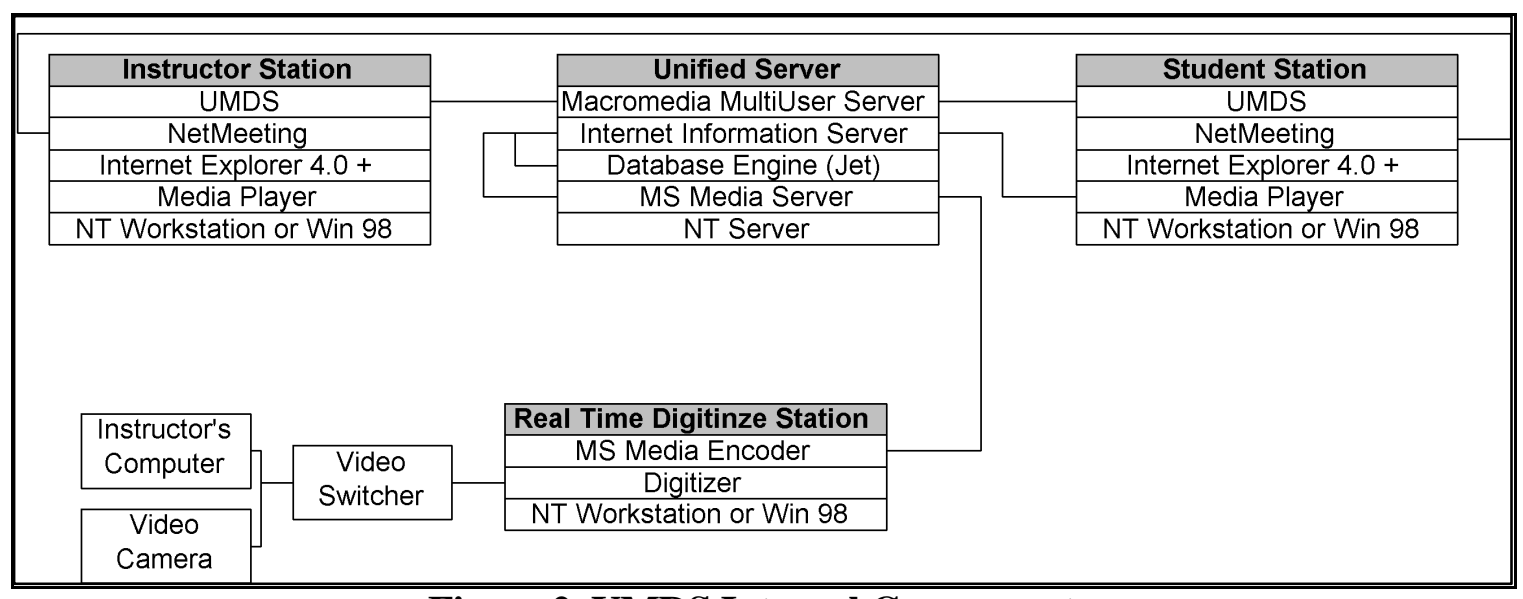

Figure 2. UMDS Internal Compone nts

\section{Conclusion}


By combining traditional CD-ROM technology with TCP/IP services, the Unified Multimedia Delivery Systems achieves a highly dynamic media-rich training environment. The traditional CD-ROM based multimedia tools available in Director 7 provide the needed ammunition to the immersive multi-sensory experience often associated with CD-ROM based products. Delivering MPEG-I, MPEG-II, and 16-bit CD quality audio is relatively easy to do with this tool.

When combined with the flexibility of server-client applications by using the TCP/IP functions provided by NetLingo, the system achieves an extremely dynamic state allowing remote administration, content updating, and performance tracking. It is this mechanism that allows CD-ROM based products to achieve the flexibility in content that once was only associated with Web applications. To exploit this new power it is imperative to follow traditional client-server programming schemes. The implementation of message loops through socket based chat connections is a necessity to allow the applications to interact.

The addition of Active- $X$ components, further extends the capabilities of the system. It allows the implementation of application components with relatively little programming. It is the pinnacle of rapid prototyping. For example, with only two method calls, it is possible to add speech synthesis to any Director 7 application. The significance is tremendous, because it virtually eliminates all boundaries from what can be achieved with Director. The individual instructor could extend the functionality of the UMDS to include course specific functionality. Those skilled in C, Visual Basic, or C++ can develop their own Active-X components using Microsoft Developed Studio.

It is the integration of these individual components and technologies that have allowed the UMDS to achieve the goal of approximating the media delivery capabilities of the traditional classroom in a distance learning system. Without the functionality provided by Director for media manipulation, NetLingo for TCP/IP communication, and the numerous Active- $\mathrm{X}$ components for specialized functions this system would not exist.

Improvements could be made to the application of the technology to specific learning problems and to the technology implemented. A more detailed analysis of the classroom activities would yield a better guide for constructing the system. It would allow the designers of the system to better map the technological solutions to the needs of the student and the instructor. Other improvements could be made by creating custom components for specific courses and by implementing a higher caliber security system, such as using the fingerprint scanner from U.R.U Inc. for identification.

In the end, this unified multimedia delivery system shows that by integrating a variety of technological solutions it is possible to build a flexible distance learning system. Within the confines of the analysis completed, the system does well at achieving its goal.

\section{Bibliography}

Abern athy, Donna, J. Training \& Development, Nov98, Vol. 52 Issue 11, p78, 2p. 
Adhikari, R. (1996). A new twist on groupware: Companies tap into intranets to share information. Information Week. November, 18th, 109.

Barrett, R. (1996). Borland pegs future on net strategy. Interactive Week. 3(24), 47-48.

Dugan, Sean. InfoWorld, 09/07/98, Vol. 20 Issue 36, p77, 1/3p.

Duvall, M. (1999). Net Consultants Challenge IT Giants. Interactive Week. V 6, no 11 march 15.

Gage, N. L., \& Berliner, D.C. (1992). Educational psychology (5th ed.). Boston, MA: Houghton Mifflin, 386-389.

Gillooly, C. (1996). Getting the ATM picture: UB Networks' app maps and monitor devices on networks. Information Week. November, 23 rd, 91-93.

Goodman, D. (1995). Education and the internet: The coming challenge to internet culture. Syllabus. 9(3), $10-12$.

Lemay, L., \& Perkins, C.L. (1996). Teach yourself Java for Macintosh in 21 days. Indianapolis, IN: Hayden Books, 148-152.

LeVitus, B. \& Evans, E. (1995). WebMaster. ChestNut Hill, MA: Academic Press, 207-227.

McGee, M.K. (1996). Multimedia-based training on the rise: Method saves on employee travel and downtime costs. Information Week. November, 23rd, 109.

Microsoft (1996). Active-X specifications. http://www.microsoft.com

Radosevich, L. (1996). Sizzle and Steak: Multimedia morphs from a pointless frill into a serious business tool. WebMaster. 1(5), 32-38.

Roberts, J. (1996). Director 5 demystified. Berkeley, CA: Peachpit Press, 531.

Robinson, T. (1996). The revolution is here: Web technology, linked to internal systems, can transform your company. Information Week. November, 18 th, 106-108.

Sergeant, D. (1995). Technology Across the Campus. Syllabus. 9(3), 30.

Seagate (1996). Hard drive specifications. http://www.seagate.com

Skinner, B.F. (1968). The technology of teaching. Appleton-Century-Crofts. A full treatment of the achievements and promises of operant conditions for improving instruction. 398.

Tucker, R.W. (1995). Distance learning programs: Models and alternatives. Syllabus. 9(3), 42-44.

Tyler, R. W. (1934). Constructing achievement test. Columbus: Ohio State University. The pioneer treatment of the role of objectives in the construction of achievement tests, especially test of complex kinds of achievement.

Welwert, C. (1984). Read or listen? A survey of the comparative studies made during the years of 18901980 concerning learning after auditory and visual presentation with an attempt to evaluate the results. Diddakometry, 69. (School of Education, Malmo, Sweden), 386.

\section{CARLOS R. MORALES}


Session 0558

Carlos R. Morales is an assistant professor of computer graphics at Purdue University at Kokomo. He holds a BA in Telecommunications and an MS Ed. in Curriculum and Instruction. Prior to working at Purdue University, Carlos worked as a

Technical Director. Some of his clients have included Microsoft, Chicago Bulls Organization, First Alert and Brach's Candies. His research interest includes distance learning, animation, and multimedia development. He can be reached at crmorales@puk.indiana.edu. 